\title{
EFEK MEDIASI KEPUASAN PADA HUBUNGAN MOTIVASI KERJA DAN ORGANIZATIONAL CITIZENSHIP BEHAVIOR
}

\section{Rini Fatmawati}

Universitas Hang Tuah, Surabaya, Jawa Timur, Indonesia

Email: rini.fatmawati@hangtuah.ac.id

\begin{abstract}
Abstrak
Dinamika bisnis dalam konteks global menarik sebagai pembahasan praktek pengelolaan organisasi dalam studi sumber daya manusia internasional. Tujuan penelitian ini adalah untuk menguji efek mediasi kepuasan kerja pada hubungan antara motivasi kerja dan organizational citizenship behavior (OCB). Metode yang dilakukan dalam penelitian menggunakan 106 karyawan sebagai responden dan menggunakan model path analysis. Hasil penelitian menunjukkan bahwa motivasi kerja memiliki hubungan positif dan signifikan dengan kepuasan kerja dan OCB, dan juga menemukan adanya hubungan positif dan signifikan antara kepuasan kerja dengan OCB. Secara umum kepuasan kerja terbukti memediasikan hubungan tersebut, tetapi spesifiknya berbeda-beda yang disebabkan oleh adanya karakteristik yang berbeda-beda diantara karyawan. Efek mediasi itu terbukti pada karyawan laki-laki, karyawan yang berusia tua ( $>40$ tahun), dan karyawan dengan masa kerja yang tinggi ( $>5$ tahun), sementara pada karyawan perempuan, karyawan yang berusia muda ( $<40$ tahun), dan karyawan dengan masa kerja yang rendah $(<5$ tahun), efek mediasi itu tidak terbukti. Adapun pada karakteristik pendidikan, tidak dapat disimpulkan secara pasti, karena variansi penjelasannya yang sangat rendah.
\end{abstract}

Kata Kunci: motivasi kerja; kepuasan kerja; organizational citizenship behavior

\section{Abstract}

Business dynamics in business in the global retract the issue of organizational management practices in the study of international human resources. The purpose of this study was to test the effect of occupational mediation on the motivation between work work and organizational citizenship behavior (OCB). The way in which in the study in the way is s 106 employees as victims and analysis of model paths. the results of the study let alone the cooperation of positive and good relationships with work and $O C B$, and also deadlocked the existence of a positive and good relationship between respect and OCB. In general, work comments let mediate the relationship, but the specifics vary, which make it between different employees in 2020. The effect of mediation has occurred on male employees, older employees ( $>40$ years), and employees of high employment ( $>5$ years), while in female employees, young employees ( $<40$ years), and low tenure employees ( $<5$ years), the effect of mediation does not exist. As for the texture of education, it can not be concluded for sure, it's a very low variance of the explanation.

\begin{tabular}{ll}
\hline How to cite: & Fatmawati, Rini (2021) Efek Mediasi Kepuasan pada Hubungan Motivasi Kerja dan Organisasional \\
& Citizenship Behavior. Syntax Literate. 6(7). http://dx.doi.org/10.36418/ syntax-literate.v6i7.3655 \\
E-ISSN: & $2548-1398$ \\
Published by: & Ridwan Institute
\end{tabular}


Keywords: motivation work; job satisfaction; organizational citizenship behavior

\section{Pendahuluan}

Organizational citizenship behavior (OCB) merupakan perilaku individu yang bersifat diskresioner yang tidak secara langsung atau eksplisit diakui oleh sistem penghargaan formal dan secara agregat mempromosikan berfungsinya organisasi secara efektif (Dennis W. Organ, 1988). Perilaku ini telah dipelajari sejak akhir tahun 1970-an, dan dalam tiga dekade terakhir, minat peneliti terhadap perilaku ini telah meningkat secara substansial. Perilaku ini telah dikaitkan dengan efektivitas organisasi secara keseluruhan, sehingga jenis perilaku karyawan ini memiliki konsekuensi yang besar di tempat kerja.

Penelitian awal mengenai antesenden OCB difokuskan pada sikap karyawan, disposisi, dan dukungan pemimpin. Baru-baru ini banyak variabel yang diperiksa dalam upaya menentukan antesenden OCB, antara lain motivasi dan kepuasan kerja. Beberapa bukti empiris telah menunjukkan bahwa motivasi berhubungan positif dengan OCB misalnya (Shareef \& Atan, 2019), (Shim \& Faerman, 2017), (Lavanya \& Kalliath, 2015), (Bourdage, Lee, Lee, \& Shin, 2012), (Finkelstein, 2011), (Barbuto Jr \& Story, 2011). Motivasi kerja yang tinggi akan meningkatkan perilaku tersebut dan sebaliknya motivasi kerja yang rendah akan memicu melemahnya perilaku tersebut. Sementara itu, hubungan antara kepuasan kerja dan perilaku tersebut juga telah banyak dilakukan, bahkan kepuasan kerja diklaim sebagai faktor yang paling signifikan dalam menjelaskan perilaku tersebut diantara antesenden yang lain. Literatur klasik, seperti (Williams \& Anderson, 1991), (Moorman, 1993), (Dennis W. Organ \& Lingl, 1995), (Foote \& Tang, 2008), telah menunjukkan bahwa adanya hubungan yang positif diantara keduanya. Demikian pula dengan literatur-literatur terbaru, seperti (Talachi, Gorji, \& Boerhannoeddin, 2014), (Swaminathan \& Jawahar, 2013), (Subhadrabandhu, 2012), (Fatimah, Amiraa, \& Halim, 2011), (Nadiri \& Tanova, 2010), (Li, Liang, \& Crant, 2010), dan (Zeinabadi, 2010).

Motivasi dan kepuasan kerja juga memiliki hubungan positif yang sangat kuat. Keduanya tidak bisa berdiri sendiri-sendiri, melainkan saling melengkapi satu sama lain. Akan tetapi, literatur klasik menyarankan agar keduanya diperlakukan secara terpisah. Hal ini dimaksudkan agar faktor-faktor yang memengaruhinya dapat diidentifikasi dengan mudah sehingga menghasilkan pemahaman yang lebih baik. Teori motivasi Herzberg yang dikembangkan melalui teori kebutuhan (Maslow, 1943), mengarahkan dua faktor motivasi (intrinsik dan ekstrinsik) kepada kepuasan kerja, karena keduanya memenuhi kebutuhan individu untuk aktualisasi diri. Sementara itu, teori harapan Porter and Lawler tahun 1968 juga mengarahkan motivasi kepada kepuasan kerja. Bukti empiris tentang hubungan keduanya juga telah banyak dilakukan dan secara umum temuannya adalah positif (misalnya (Breaugh, Ritz, \& Alfes, 2018), (Homberg, McCarthy, \& Tabvuma, 2015), (Ncube \& Samuel, 2014). Dengan demikian, ada kecenderungan yang besar bahwa hubungan antara motivasi kerja dan OCB tidak langsung melainkan melalui kepuasan kerja. Motivasi yang tinggi akan mendorong 
kepuasan kerja yang tinggi dan selanjutnya akan meningkatkan OCB. Sebaliknya, penurunan motivasi kerja akan menurunkan kepuasan yang pada akhirnya akan mengurangi OCB. Jadi, kepuasan kerja akan berperan sebagai mediator pada hubungan tersebut.

Konsep Organizational Citizenship Behavior (OCB) digagas oleh Dennis Organ, yang dikembangkan berdasarkan karya asli dari Katz pada tahun 1964. OCB didefinisikan sebagai perilaku individu yang bersifat diskresioner tidak secara langsung atau eksplisit diakui oleh sistem penghargaan formal dan secara agregat mempromosikan fungsinya organisasi secara efektif (Dennis W. Organ, 1988). Makna sederhana dari OCB adalah sebuah perilaku kecintaan individu terhadap organisasinya, dimana ia bersedia memberikan segala potensi yang dimilikinya untuk membangun atau mengembangkan organisasinya, meskipun itu bukan dari bagian pekerjaan formalnya bahkan untuk itu ia bersedia melakukannya dengan sukarela. Seseorang dengan OCB yang tinggi akan melihat pekerjaannya melebihi dari sekedar gaji dan berusaha untuk melakukan semua yang bisa dilakukannya untuk membuat lingkungan kerjanya berjalan lancar bahkan meskipun semua itu tidak memiliki hubungan langsung dengan tugas formalnya. Perilaku ini tentu saja akan sangat berdampak positif bagi organisasi.

Penelitian tentang OCB telah banyak dilakukan (Michael G. Organ et al., 2006) menawarkan lima dimensi dari OCB, yaitu: (1) Altruism, yang mengarahkan pada perilaku seseorang untuk menolong rekan kerjanya yang mengalami kesulitan, baik berkaitan dengan tugas pekerjaannya maupun terkait masalah pribadi; (2) conscientiousness, yang mengarahkan pada perilaku seseorang untuk berusaha melebihi harapan organisasi; (3) Sportmanship, yang mengarahkan pada perilaku toleransi seseorang terhadap keadaan yang kurang ideal dalam organisasi tanpa mengajukan keberatan-keberatan; (4) Courtessy, mengarahkan perilaku seseorang untuk menghindari masalah-masalah interpersonal dengan sesama rekan kerjanya; dan (5) civil viretue, mengarahkan pada perilaku tanggung jawab seseorang pada kehidupan organisasinya. Penelitian awal mengenai antesenden OCB difokuskan pada sikap karyawan, disposisi, dan dukungan pemimpin. Baru-baru ini, banyak variabel yang diperiksa dalam upaya menentukan antesenden OCB, antara lain motivasi dan kepuasan kerja.

Motivasi baik intrinsik maupun ekstrinsik diyakini mempunyai hubungan yang positif dengan OCB. Motivasi kerja yang tinggi akan mendorong OCB yang tinggi dan sebaliknya motivasi yang rendah akan memicu penurunan OCB. Motivasi kerja merupakan kekuatan psikologis seorang pekerja untuk meningkatkan semangat dalam pekerjaannya. Motivasi kerja terdiri dari motivasi intrinsik dan ekstrinsik (George, Jones, \& Sharbrough, 2005). Motivasi intrinsik merupakan perilaku yang ditunjukkan untuk kepentingan diri sendiri, sedangkan motivasi ekstrinsik adalah perilaku yang ditujukan untuk mendapatkan materi atau penghargaan sosial atau untuk menghindari hukuman. (Luthans, Youssef, \& Rawski, 2011) mengemukakan bahwa ada lima indikator dari motivasi intrinsik: (1) achievement, yaitu motivasi yang didorong rasa bangga atas keberhasilan seseorang terhadap pekerjaan; (2) recognition, yaitu motivasi 
seorang pekerja yang didorong oleh adanya pengakuan orang-orang atau rekan kerja atau atau atasannya terhadap keberhasilan yang telah dilakukannya; (3) work itself, yang merupakan motivasi seorang pekerja terhadap pekerjaan itu sendiri; (4) responsibility, yaitu motivasi seorang pekerja yang didorong oleh adanya tanggung jawab atau wewenang penuh kepada dirinya terhadap pekerjaan yang dilakukannya; dan (5) advancement, yaitu motivasi seorang pekerja yang didorong oleh adanya unsur-unsur pengembangan. Sementara itu, (Luthans et al., 2011) juga mengemukakan lima indikator untuk motivasi ekstrinsik, yaitu: (1) policy and administration, yaitu motivasi yang didorong dari kebijakan dan administrasi organisasi yang baik; (2) quality supervisor, yaitu motivasi yang didorong oleh kualitas supervisor; (3) interpersonal relation, yaitu motivasi yang didorong oleh hubungan interpersonal; (4) working condition, yaitu motivasi yang didorong oleh kondisi pekerjaan itu sendiri; dan wages, yaitu motivasi yang didorong oleh gaji. Secara spesifik, hubungan motivasi kerja dan OCB juga sudah banyak diuji, dengan hasil yang positif, antara lain oleh (Shareef \& Atan, 2019), (Shim \& Faerman, 2017), (Lavanya \& Kalliath, 2015), (Bourdage et al., 2012), (Finkelstein, 2011), (Barbuto Jr \& Story, 2011).

Selain berhubungan dengan $\mathrm{OCB}$, motivasi kerja juga memiliki hubungan yang erat dengan kepuasan kerja. Hubungan keduanya secara eksplisit dijelaskan dalam teori dua faktor, Herzberg, yang merupakan pengembangan dari teori Maslow dan juga berhubungan erat dengan teori tiga faktor sosial, McClelland. Teori ini menjelaskan bahwa ada faktor-faktor tertentu di tempat kerja yang menyebabkan kepuasan kerja, sementara pada bagian yang lain ada pula faktor yang menyebabkan ketidakpuasan kerja. Salah satu faktor yang dimaksud adalah motivasi, yang berperan sebagai faktor pemuas pada pekerjaan. Faktor motivasi dikaitkan dengan konten pekerjaan, termasuk keberhasilan, pengakuan, pekerjaan yang menantang, peningkatan dan pertumbuhan dalam pekerjaan. Berbagai hasil kajian empiris juga telah membuktikan bahwa motivasi memiliki hubungan positif yang signifikan dengan kepuasan kerja, dimana motivasi yang tinggi akan meningkatkan kepuasan kerja, dan motivasi yang rendah dapat memicu ketidakpuasan kerja. Dengan demikian, ada kecenderungan yang besar bahwa hubungan antara motivasi kerja dan OCB tidak langsung, melainkan melalui kepuasan kerja. Motivasi yang tinggi akan mendorong kepuasan kerja yang tinggi, dan selanjutnya akan meningkatkan OCB. Sebaliknya, penurunan motivasi kerja akan menurunkan kepuasan, yang pada akhirnya akan mengurangi OCB. Jadi, kepuasan kerja akan berperan sebagai mediator pada hubungan mereka, dan paper ini akan pergi untuk membuktikannya.

Tujuan penelitian ini adalah untuk menguji efek moderasi dari kepuasan kerja pada hubungan antara motivasi kerja dan OCB. Spesifiknya, penelitian ini akan menjawab apakah kepuasan kerja memediasikan hubungan tersebut atau tidak.

\section{Metode Penelitian}

Data penelitian diperoleh dari penyebaran angket secara acak kepada 150 orang karyawan yang bekerja di seantero Kota Surabaya, Indonesia, namun hanya 106 angket 
yang kembali dan dapat digunakan. Angket terdiri dari 23 pertanyaan tertutup, yang semuanya diukur dengan lima skala likert, yaitu: (1) sangat tidak setuju, (2) tidak setuju, (3) ragu-ragu, (4) setuju, dan (5) sangat setuju.

Organizational citizenship behavior (OCB) diukur dengan lima item pertanyaan untuk lima dimensi yang dikemukakan (Michael G. Organ et al., 2006), yaitu altruism, conscientiousness, sportmanship, courtessy, dan civil viretue. Sedangkan motivasi kerja diukur dengan sepuluh item pertanyaan, yang mencakup lima pertanyaan untuk motivasi intrinsik dan sisanya untuk motivasi ekstrinsik. Kedua tipe motivasi ini didasari pada indikator yang dikemukakan oleh (Luthans et al., 2011), yaitu achievement, recognition, work itself, responsibility, dan advancement untuk motivasi intrinsik, dan policy and administration, quality supervisor, interpersonal relation, working condition, dan wages untuk motivasi ekstrinsik. Adapun kepuasan kerja diukur dengan delapan pertanyaan untuk delapan indikator yang dikemukakan (Hasibuan, 2001), yaitu kesetiaan, kemampuan, kejujuran, kreativitas, kepemimpinan, gaji, kompensasi tidak langsung, dan lingkungan kerja.

Model analisis data menggunakan path analysis. Model matematis yang dikembangkan untuk model tersebut adalah:

Satisfaction $=\beta_{M}$ Motivation $+\varepsilon$ Model 1

$O C B=\beta_{M}$ Motivation $+\beta_{S}$ Satisfaction $+\varepsilon$ Model 2

\section{Hasil dan Pembahasan}

Hasil penelitian menunjukkan bahwa motivasi berhubungan positif dan signifikan dengan kepuasan kerja, dan juga berhubungan positif dengan OCB (Shareef \& Atan, 2019), (Shim \& Faerman, 2017), (Lavanya \& Kalliath, 2015), (Bourdage et al., 2012), (Finkelstein, 2011), (Barbuto Jr \& Story, 2011). Sementara itu, kepuasan juga memiliki hubungan yang positif dan signifikan dengan OCB. Hubungan positif antara motivasi dan kepuasan cukup kuat $(\mathrm{R} 2=55.5 \%)$, tetapi kemampuan motivasi untuk menjelaskan kepuasan tergolong lemah (adj. r-square $=30.5 \%$ ). Sementara itu, hubungan antara motivasi dan OCB sangat kuat $(\mathrm{R} 2=90.6 \%)$ dan kemampuannya untuk menjelaskan OCB sangat tinggi (adj. r-square $=82 \%$ ). Adapun hubungan antara kepuasan dan OCB lebih rendah $(\mathrm{R} 2=62.5 \%)$ dibandingkan dengan hubungan motivasi dan OCB, dan kemampuannya untuk menjelaskan OCB juga lebih rendah (adj. r-square $=38.8 \%$ ). Dengan demikian, kepuasan kerja tidak terbukti memediasikan hubungan antara motivasi dan OCB karena keduanya mempunyai hubungan langsung. Spesifiknya, hubungan-hubungan itu dapat dilihat pada Gambar 1 dan Tabel 1. 


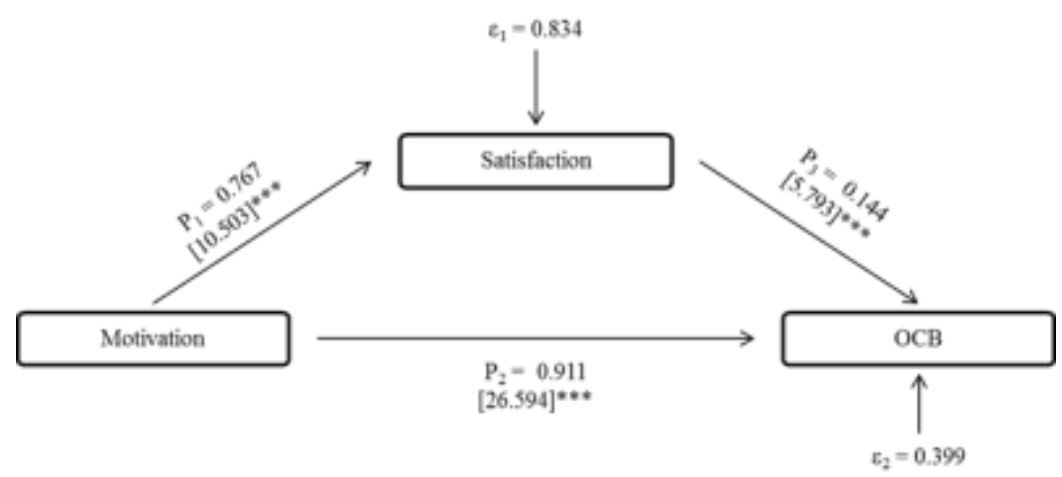

Gambar 1

Hubungan Motivasi, Kepuasan, dan OCB

Tabel 1

Hasil Analisis Data

\begin{tabular}{|c|c|c|c|c|c|c|c|}
\hline & \multicolumn{3}{|c|}{ Model 1} & \multicolumn{2}{|c|}{ Model 2} & \multirow{2}{*}{$M$} & \multirow{2}{*}{ Decision } \\
\hline & \multirow[t]{2}{*}{$\boldsymbol{\beta}$} & $\varepsilon$ & $t$ & \multirow[t]{2}{*}{$\varepsilon$} & \multirow[t]{2}{*}{$t$} & & \\
\hline \multicolumn{5}{|l|}{ Panel A. Umum } & & & \\
\hline Motivasi Kerja & \multirow[t]{2}{*}{0.767} & \multirow[t]{2}{*}{0.073} & \multirow{2}{*}{\multicolumn{2}{|c|}{$\begin{array}{r}10.503 * * * 0.9110 .034 \\
0.1440 .025\end{array}$}} & $26.594 * * *$ & \multirow{2}{*}{0.110} & \multirow{2}{*}{ Direct } \\
\hline Kepuasan Kerja & & & & & $5.793 * * *$ & & \\
\hline \multicolumn{8}{|c|}{ Panel B.Perspektif Genre } \\
\hline \multicolumn{8}{|c|}{ Laki-laki } \\
\hline Motivasi Kerja & \multirow[t]{2}{*}{0.535} & \multirow[t]{2}{*}{0.103} & \multirow{2}{*}{\multicolumn{2}{|c|}{$\begin{array}{r}5.171 * * * 0.3170 .084 \\
0.4900 .065\end{array}$}} & $3.782 * * *$ & \multirow{2}{*}{0.262} & \multirow{2}{*}{ Direct } \\
\hline Kepuasan Kerja & & & & & $7.555 * * *$ & & \\
\hline \multicolumn{8}{|l|}{ Perempuan } \\
\hline Motivasi Kerja & \multirow[t]{2}{*}{0.491} & \multirow[t]{2}{*}{0.107} & \multirow{2}{*}{\multicolumn{2}{|c|}{$\begin{array}{r}4.575 * * * 0.1080 .140 \\
0.3340 .111\end{array}$}} & 0.769 & \multirow{2}{*}{0.164} & \\
\hline Kepuasan Kerja & & & & & $2.998 * * *$ & & \\
\hline Panel C. Perspektif & & & & & & & \\
\hline Tua (>40 tahun) & & & & & & & \\
\hline Motivasi Kerja & 0.625 & 0.127 & $4.933 * * * 0.100$ & 0.108 & 0.930 & & \\
\hline Kepuasan Kerja & & & 0.556 & 0.085 & $6.516 * * *$ & .040 & Inatrect \\
\hline Muda (<40 tahun) & & & & & & & \\
\hline Motivasi Kerja & 0.521 & 0.091 & $5.702 * * * 0.344$ & 0.331 & $4.759 * * *$ & & \\
\hline Kepuasan Kerja & & & 0.265 & 0.332 & $4.767 * * *$ & & Direct \\
\hline Panel D. Perspektif & Kerja & & & & & & \\
\hline Masa Kerja Tinggi & & & & & & & \\
\hline 5 Thn.) & & & & & & & \\
\hline Motivasi Kerja & 0.726 & 0.184 & $3.935 * * *-0.067$ & 0.153 & -0.441 & & \\
\hline Kepuasan Kerja & & & 0.569 & 0.091 & $6.227 * * *$ & 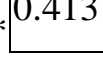 & idirect \\
\hline $\begin{array}{l}\text { Masa Kerja Rendah } \\
(<5 \text { Thn.) }\end{array}$ & & & & & & & \\
\hline Motivasi Kerja & 0.461 & 0.103 & $4.461 * * * 0.270$ & 0.081 & $3.323 * * *$ & & Divect \\
\hline Kepuasan Kerja & & & 0.445 & 0.056 & $7.993 * * *$ & & Direct \\
\hline Panel E. Perspektif I & idikan & & & & & & \\
\hline Pendidikan Tinggi & & & & & & & \\
\hline Motivasi Kerja & 0.482 & 0.097 & $4.968 * * * 0.218$ & 0.086 & $2.526 * *$ & & \\
\hline Kepuasan Kerja & & & 0.305 & 0.065 & $4.693 * * *$ & & Direct \\
\hline Pendidikan Rendah & & & & & & & \\
\hline Motivasi Kerja & 0.588 & 0.130 & $4.508 * * * 0.301$ & 0.107 & $2.812 * * *$ & & Direct \\
\hline Kepuasan Kerja & & & 0.432 & 0.080 & $5.372 * * *$ & & Direct \\
\hline
\end{tabular}


$\overline{\text { Independent variable model 1: job satisfaction; Independent variable model 2: organizational }}$ citizenship behavior

*** significant at the $1 \%$ level; ** significant at the 5\% level; * significant at the $10 \%$ level

Sumber: data primer yang diolah, 2021

Terkait hubungan antara motivasi dan kepuasan, motivasi intrinsik dan ekstrinsik sama-sama memberikan kontribusi yang signifikan terhadap kepuasan, namun kontribusi motivasi ekstrinsik lebih mendominasinya. Semua indikator motivasi, baik intrinsik maupun ekstrinsik signifikan meningkatkan kepuasan. Kepuasan terkait kemampuan terhadap hasil kerja tidak berkaitan dengan kedua motivasi tersebut. Selain dengan kepuasan, motivasi juga berhubungan positif dan langsung dengan OCB. Motivasi intrinsik dan ekstrinsik juga sama-sama memberikan kontribusi yang signifikan terhadapnya. Semua indikator motivasi, kecuali motivasi terkait advancement dan gaji, signifikan meningkatkan OCB, baik yang berkaitan dengan altruism, conscientiousness, sportmanship, courtessy, maupun civil virtue. Sementara itu, kepuasan juga berhubungan positif dengan OCB. Semua indikator kepuasan signifikan meningkatkan OCB.

Meskipun secara umum kepuasan kerja tidak terbukti memediasikan hubungan antara motivasi kerja dan OCB hal tersebut tidak mendukung (Breaugh et al., 2018), (Homberg et al., 2015), (Ncube \& Samuel, 2014), namun spesifiknya disetiap karyawan berbeda-beda. Pada perspektif gender, efek mediasi kepuasan pada hubungan motivasi dan OCB terbukti pada karyawan perempuan, tetapi tidak pada karyawan laki-laki. Pada karyawan laki-laki, selain berhubungan positif dengan kepuasan, motivasi secara langsung juga berhubungan positif dengan OCB. Disamping itu, kepuasan juga berhubungan positif dengan OCB. Motivasi intrinsik dan ekstrinsik signifikan meningkatkan kepuasan kerja mereka, namun motivasi ekstrinsik lebih mendominasinya. Secara substansial, kedua motivasi itu akan meningkatkan kepuasan terkait kemampuan terhadap hasil kerja, kreativitas terhadap hasil pekerjaan, supervisor atau pimpinan, gaji, dan lingkungan kerja. Terkait dengan motivasi dan OCB, hanya motivasi intrinsik yang signifikan, terutama yang berkaitan dengan recognition. Peningkatan motivasi terkait recognition akan meningkatkan OCB terkait civil viretue. Sementara itu, kepuasan terkait supervisor atau pemimpin, gaji, dan kompensasi tidak langsung signifikan meningkatkan OCB mereka, terutama yang berkaitan dengan conscientiousness, sportmanship, dan civil viretue. Hubungan motivasi dan kepuasan pada karyawan laki-laki lebih rendah daripada hubungannya dengan OCB (R2 $=18.5 \%$ vs. $39.0 \%$ ), demikian pula variansi penjelasannya (adj. r-square $=2.6 \%$ vs. $14.4 \%$ ). Sementara itu, hubungan antara kepuasan dan OCB cukup kuat $(\mathrm{R} 2=31.5 \%)$, namun variansi penjelasannya sangat lemah (adj. $r$-square $=9.1 \%$ ). Sedangkan pada karyawan perempuan, motivasi intrinsik dan ekstrinsik signifikan meningkatkan kepuasan mereka, terutama terkait dengan kemampuan terhadap hasil pekerjaan, supervisor atau pimpinan, gaji, kompensasi tidak langsung, dan lingkungan kerja. Secara substansial, kepuasankepuasan tersebut akan mendorong OCB mereka terutama yang berkaitan dengan 
conscientiousness, sportmanship, courtessy, dan civil viretue. Hubungan motivasi dan kepuasan cukup kuat $(\mathrm{R} 2=41.4 \%)$, tetapi variansi penjelasannya sangat rendah (adj. $\mathrm{r}$ square $=16.5 \%$ ), sementara hubungan kepuasan dan OCB juga cukup kuat dan variansi penjelasannya cukup tinggi (adj. r-square $=40.9 \%$ ).

Perspektif usia, efek mediasi kepuasan pada hubungan motivasi dan OCB juga terbukti pada karyawan berusia tua ( $>40$ tahun). Motivasi intrinsik dan ekstrinsik signifikan meningkatkan kepuasan, terutama yang berkaitan dengan supervisor, gaji, kompensasi tidak langsung, dan lingkungan kerja. Secara substansial, kepuasankepuasan itu akan mendorong OCB, terutama terkait conscientiousness, sportmanship, courtessy, dan civil viretue. Pada karyawan yang berusia tua, hubungan motivasi dan kepuasan lebih tinggi dibandingkan dengan hubungannya dengan OCB ( $2=49.5 \%$ vs. 40.5\%), demikian pula dengan determinasinya (adj. r-square $=23.5 \%$ vs. $15.3 \%$ ). Sementara itu, hubungan kepuasan dan OCB jauh lebih kuat $(\mathrm{R} 2=68 \%)$ daripada hubungan motivasi dan OCB, demikian pula determinasinya (adj. r-square $=45.5 \%$ ). Sedangkan pada karyawan yang berusia muda ( $<40$ tahun), efek mediasi tersebut tidak terbukti. Motivasi mempunyai hubungan langsung dengan OCB, meskipun motivasi juga memiliki hubungan positif signifikan dengan kepuasan, dan kepuasan dengan OCB. Motivasi intrinsik dan ekstrinsik (terutama) secara langsung akan meningkatkan OCB. Sementara itu, kedua motivasi itu juga signifikan meningkatkan kepuasan mereka, terutama yang berkaitan dengan kemampuan terhadap hasil kerja, kejujuran dalam bekerja, supervisor, gaji, kompensasi tidak langsung, dan lingkungan kerja. Secara substansial, kepuasan-kepuasan itu akan meningkatkan OCB, terutama yang berkaitan dengan conscientiousness, sportmanship, courtessy, dan civil viretue. Hubungan motivasi dan OCB lebih kuat dibandingkan dengan hubungannya dengan kepuasan $(\mathrm{R} 2=46.4 \%$ vs. $40.0 \%$ ), demikian pula determinasinya (adj. r-square = $21.1 \%$ vs. $15.5 \%$ ). Adapun hubungan kepuasan dengan OCB sama kuatnya dengan hubungan motivasi dan OCB, demikian pula variansi penjelasannya.

Perspektif masa kerja, efek mediasi itu juga terbukti pada karyawan yang masa kerja tinggi. Motivasi, baik intrinsik maupun ekstrinsik tidak memiliki hubungan yang signifikan dengan OCB. Hanya motivasi ekstrinsik (terutama yang terkait dengan quality supervisor, interpersonal relation, dan working condition) yang berhubungan positif signifikan dengan kepuasan, terutama yang berkaitan dengan kejujuran dalam bekerja, kompensasi tidak langsung, dan lingkungan kerja. Secara substansial kepuasankepuasan itu signifikan meningkatkan OCB, terutama yang berkaitan dengan conscientiousness, sportmanship, dan courtessy. Hubungan motivasi dan kepuasan memang cukup kuat $(\mathrm{R} 2=43.3 \%$ ), namun determinasinya sangat rendah (adj. r-square $=17.6 \%)$. Sementara itu, hubungan kepuasan dan OCB tergolong lemah $(\mathrm{R} 2=23.8 \%)$, dan determinasinya juga sangat rendah (adj. r-square $=4.2 \%$ ). Sebaliknya pada karyawan masa kerja rendah. Efek moderasi kepuasan pada hubungan itu tidak terbukti. Motivasi, baik internal maupun eksternal mempunyai hubungan positif signifikan dan langsung dengan OCB, terutama yang berkaitan dengan altruism, conscientiousness, sportmanship, dan civil viretue. Hubungan ini cukup kuat $(\mathrm{R} 2=46.7 \%)$, namun 
determinasinya masih rendah (adj. $r$-square $=19.6 \%$ ). Sementara itu, motivasi intrinsik dan ekstrinsik juga memiliki hubungan positif signifikan dengan kepuasan, terutama terkait kreativitas terhadap hasil, supervisor, gaji, kompensasi tidak langsung, dan lingkungan kerja. Hubungannya juga cukup kuat $(\mathrm{R} 2=43.2 \%)$, namun determinasinya juga masih tergolong rendah (adj. r-square $=14.9 \%$ ). Adapun kepuasan dan OCB memiliki hubungan positif dan kuat $(\mathrm{R} 2=67.20 \%)$, dengan determinasi yang juga cukup kuat (adj. r-square $=43.6 \%$ ). Kepuasan terkait kemampuan, kejujuran, kreativitas, kepemimpinan, gaji, kompensasi tidak langsung, dan lingkungan kerja memiliki kontribusi yang signifikan dalam meningkatkan OCB, terutama terkait conscientiousness, sportmanship, courtessy, dan civil viretue.

Perspektif pendidikan, efek mediasi kepuasan pada hubungan motivasi dan OCB tidak terbukti, baik pada karyawan yang berpendidikan tinggi (sarjana dan setelahnya) maupun berpendidikan rendah (diploma dan sebelumnya). Pada karyawan yang berpendidikan tinggi, hubungan motivasi dan OCB adalah positif dan signifikan, namun hubungan itu tergolong lemah $(\mathrm{R} 2=31.8 \%)$, demikian pula determinasinya (adj. $\mathrm{r}$ square $=9.6 \%$ ). Sementara hubungan motivasi dan kepuasan hanya sedikit lebih kuat daripada hubungannya dengan OCB $(\mathrm{R} 2=36.4 \%)$, dan determinasinya juga sangat rendah (adj. r-square $=12.7 \%$ ). Adapun hubungan kepuasan dan OCB memang cukup kuat $(\mathrm{R} 2=42.2 \%)$, tetapi determinasinya masih sangat rendah $($ adj. $r$-square $=17.3 \%)$. Spesifiknya, motivasi intrinsik dan ekstrinsik hanya signifikan meningkatkan OCB terkait conscientiousness dan civil viretue. Sementara itu, kedua motivasi itu hanya berdampak positif terhadap kepuasan terkait kejujuran dalam bekerja, kreativitas terhadap hasil kerja, supervisor, gaji, dan lingkungan kerja. Secara substansial, kepuasan-kepuasan tersebut hanya akan berdampak positif terhadap OCB terkait conscientiousness, sportmanship, courtessy, dan civil viretue. Namun demikian, semua model menunjukkan determinasi yang sangat rendah (adj. r-square $<20 \%$ ). Berbeda pada karyawan yang berpendidikan rendah, hubungan motivasi dan OCB lebih kuat dibandingkan dengan hubungannya dengan kepuasan dan hubungan kepuasan dengan OCB (R2 $=61.2 \%$ vs. $44.1 \%$ vs. $47.9 \%)$, demikian pula determinasinya (adj. $r$-square = $36.7 \%$ vs. $18.5 \%$ vs. $22.1 \%$ ). Motivasi, baik intrinsik maupun ekstrinsik secara langsung dapat meningkatkan OCB, terutama terkait altruism, conscientiousness, sportmanship, dan civil viretue. Sementara itu, kedua motivasi itu juga signifikan meningkatkan kepuasan, dan kepuasan tersebut signifikan meningkatkan OCB (Williams \& Anderson, 1991), (Moorman, 1993), (Dennis W. Organ \& Lingl, 1995), (Foote \& Tang, 2008).

\section{Kesimpulan}

Secara umum kepuasan kerja terbukti memediasikan hubungan antara motivasi kerja dan OCB. Namun spesifiknya berbeda-beda, yang disebabkan oleh adanya karakteristik yang berbeda-beda diantara karyawan. Jadi, hubungan antara motivasi kerja, kepuasan kerja, dan OCB sangat bergantung pada karakteristik demografi karyawan. Bagi karyawan perempuan motivasi dapat meningkatkan OCB secara 
langsung, namun tidak bagi karyawan laki-laki. Bagi karyawan laki-laki, motivasi tidak serta-merta meningkatkan OCB, melainkan memerlukan proses lain, salah satunya melalui peningkatan kepuasan kerja. Selain itu, karyawan yang berusia muda, dan masa kerja rendah, motivasi juga dapat meningkatkan OCB dengan cepat. Sebaliknya, karyawan yang berusia tua, dan masa kerja tinggi, motivasi, baik intrinsik maupun ekstrinsik tidak serta-merta meningkatkan OCB. Akan tetapi, memerlukan proses lain, antara lain melalui peningkatan kepuasan kerja. Setelah kepuasan sudah terpenuhi, maka barulah OCB tercipta. Adapun pada karakteristik pendidikan, tidak dapat disimpulkan secara pasti, karena variansi penjelasannya yang sangat rendah. Temuantemuan ini mendukung penuh hipotesis pertama $(\mathrm{H} 1)$, kedua $(\mathrm{H} 2)$, dan ketiga $(\mathrm{H} 3)$. Sedangkan hipotesis inti, yaitu hipotesis keempat (H4) didukung sebagian. 


\section{BIBLIOGRAFI}

Barbuto Jr, John E., \& Story, Joana S. P. (2011). Work motivation and organizational citizenship behaviors: A field study. Journal of Leadership Studies, 5(1), 23-34. Google Scholar

Bourdage, Joshua S., Lee, Kibeom, Lee, Jong Hyun, \& Shin, Kang Hyun. (2012). Motives for organizational citizenship behavior: Personality correlates and coworker ratings of OCB. Human Performance, 25(3), 179-200. Google Scholar

Breaugh, Jessica, Ritz, Adrian, \& Alfes, Kerstin. (2018). Work motivation and public service motivation: disentangling varieties of motivation and job satisfaction. Public Management Review, 20(10), 1423-1443. Google Scholar

Fatimah, O., Amiraa, A. M., \& Halim, F. W. (2011). The relationships between organizational justice, organizational citizenship behavior and job satisfaction. Pertanika J. Soc. Sci. \& Hum, 19(5), 115-121. Google Scholar

Finkelstein, Marcia A. (2011). Intrinsic and extrinsic motivation and organizational citizenship behavior: A functional approach to organizational citizenship behavior. Journal of Psychological Issues in Organizational Culture, 2(1), 19-34. Google Scholar

Foote, David A., \& Tang, Thomas Li-Ping. (2008). Job satisfaction and organizational citizenship behavior (OCB): Does team commitment make a difference in selfdirected teams? Management Decision. Google Scholar

George, Jennifer M., Jones, Gareth R., \& Sharbrough, William C. (2005). Understanding and managing organizational behavior. Pearson Prentice Hall Upper Saddle River, NJ. Google Scholar

Hasibuan, Muhammad Rizal. (2001). Pengaruh Karakteristik Perusahaan Terhadap Pengungkapan Sosial (Social Disclosures) Dalam Laporan Tahunan Emitmen Di Bursa Efek Jakarta Dan Bursa Efek Surabaya. program Pascasarjana Universitas Diponegoro. Google Scholar

Homberg, Fabian, McCarthy, Dermot, \& Tabvuma, Vurain. (2015). A meta-analysis of the relationship between public service motivation and job satisfaction. Public Administration Review, 75(5), 711-722. Google Scholar

Lavanya, T., \& Kalliath, Namrata Alice Mani. (2015). Work Motivation and Leadership Styles in relation to Organizational Citizenship Behavior. Annamalai International Journal of Business Studies \& Research. Google Scholar

Li, Ning, Liang, Jian, \& Crant, J. Michael. (2010). The role of proactive personality in job satisfaction and organizational citizenship behavior: a relational perspective. Journal of Applied Psychology, 95(2), 395. Google Scholar 
Luthans, Fred, Youssef, Carolyn M., \& Rawski, Shannon L. (2011). A tale of two paradigms: The impact of psychological capital and reinforcing feedback on problem solving and innovation. Journal of Organizational Behavior Management, 31(4), 333-350. Google Scholar

Maslow, Abraham H. (1943). Preface to motivation theory. Psychosomatic Medicine. Google Scholar

Moorman, Robert H. (1993). The influence of cognitive and affective based job satisfaction measures on the relationship between satisfaction and organizational citizenship behavior. Human Relations, 46(6), 759-776. Google Scholar

Nadiri, Halil, \& Tanova, Cem. (2010). An investigation of the role of justice in turnover intentions, job satisfaction, and organizational citizenship behavior in hospitality industry. International Journal of Hospitality Management, 29(1), 33-41. Google Scholar

Ncube, Chrisbel M., \& Samuel, Michael O. (2014). Revisiting employee motivation and job satisfaction within the context of an emerging economy: Theoretical representation and developing the model. Mediterranean Journal of Social Sciences, 5(9), 267. Google Scholar

Organ, Dennis W. (1988). Organizational citizenship behavior: The good soldier syndrome. Lexington Books/DC Heath and Com. Google Scholar

Organ, Dennis W., \& Lingl, Andreas. (1995). Personality, satisfaction, and organizational citizenship behavior. The Journal of Social Psychology, 135(3), 339-350. Google Scholar

Organ, Michael G., Avola, Stephanie, Dubovyk, Igor, Hadei, Niloufar, Kantchev, Eric Assen B., O'Brien, Christopher J., \& Valente, Cory. (2006). A User-Friendly, AllPurpose $\mathrm{Pd}-\mathrm{NHC}(\mathrm{NHC}=\mathrm{N}-\mathrm{Heterocyclic}$ Carbene $)$ Precatalyst For The Negishi Reaction: A Step Towards A Universal Cross-Coupling Catalyst. Chemistry-A European Journal, 12(18), 4749-4755. Google Scholar

Shareef, Raad Abdulkareem, \& Atan, Tarik. (2019). The Influence Of Ethical Leadership On Academic Employees' Organizational Citizenship Behavior And Turnover Intention: Mediating Role Of Intrinsic Motivation. Management Decision. Google Scholar

Shim, Dong Chul, \& Faerman, Sue. (2017). Government Employees' Organizational Citizenship Behavior: The Impacts Of Public Service Motivation, Organizational Identification, And Subjective OCB Norms. International Public Management Journal, 20(4), 531-559. Google Scholar

Subhadrabandhu, Thanya. (2012). Job Satisfaction And Organizational Citizenship Behavior Of Personnel At One University Hospital In Thailand. Journal of the Medical Association of Thailand, 95(6), S102-S108. Google Scholar 
Rini Fatmawati

Swaminathan, Samanvitha, \& Jawahar, P. David. (2013). Job Satisfaction As A Predictor Of Organizational Citizenship Behavior: An Empirical Study. Global Journal of Business Research, 7(1), 71-80. Google Scholar

Talachi, Rahil Kazemi, Gorji, Mohammad Bagher, \& Boerhannoeddin, Ali Bin. (2014). An Investigation Of The Role Of Job Satisfaction In Employees' Organizational Citizenship Behavior. Collegium Antropologicum, 38(2), 429-436. Google Scholar

Williams, Larry J., \& Anderson, Stella E. (1991). Job Satisfaction And Organizational Commitment As Predictors Of Organizational Citizenship And In-Role Behaviors. Journal of Management, 17(3), 601-617. Google Scholar

Zeinabadi, Hassanreza. (2010). Job Satisfaction And Organizational Commitment As Antecedents Of Organizational Citizenship Behavior (OCB) Of Teachers. Procedia-Social and Behavioral Sciences, 5, 998-1003. Google Scholar

\section{Copyright holder:}

Rini Fatmawati (2021)

First publication right:

Journal Syntax Literate

This article is licensed under: 